\title{
Derechos indemnizatorios derivados de la extinción del contrato predoctoral: ¿Cabe indemnización por finalización de contrato cuando la misma se encuentra prevista de forma expresa en el mismo? A propósito de las SSTSJ de Asturias de 23 y 30 de junio de 2020*
}

\author{
Entitlement to compensation due to the termination \\ of the predoctoral contract: Is there entitlement to compensation \\ due to contract termination when it is expressly provided \\ for in it? Regarding the rulings of the Asturias High Court \\ of 23 and 30 June 2020
}

Josep Moreno Gené ${ }^{* *}$

Profesor Titular de Derecho del Trabajo y de la Seguridad Social

Universidad de Lleida

ORCID ID: 0000-0001-7908-0231

Recibido: 6/10/2020

Aceptado: 6/11/2020

doi: https://doi.org/10.20318/labos.2021.6048

Resumen: Una de las cuestiones más conflictivas que plantea el contrato predoctoral es la de determinar si a la finalización del mismo los investigadores que lo han suscrito tienen o no derecho a percibir indemnización alguna. Frustrada la posibilidad de dotar de indemnización por finalización de contrato a estos supuestos en base a la normativa comunitaria, se plantea la posibilidad de reclamar una indemnización en base a la normativa nacional y, en particular, al art. 49.1.c) ET, que prevé que a la finalización del contrato, excepto en los casos del contrato de interinidad y de los contratos formativos, el trabajador tendrá derecho a recibir una indemnización equivalente a doce días de salario por año de servicios. Pues bien, es en este punto donde se incardinan sendas sentencias del TSJ de Asturias de 23 y 30 de junio de 2020 objeto de este comentario que abordan específicamente esta cuestión, con la particularidad añadida de que, en este supuesto, el derecho a percibir una indemnización por finalización del contrato,

*Este trabajo se ha elaborado en el marco del proyecto de investigación RTI2018-097947-B-I00, concedido por el Ministerio de Ciencia, Innovación y Universidades que lleva por título "Nuevas tecnologías, cambios organizativos y trabajo: una visión multidisciplinar" (www.tecnologiaytrabajo.com).

"El autor es miembro del grupo de investigación consolidado reconocido por la Generalitat de Cataluña "Social and Business Research Laboratory" (SBRLab). Ref. 2017 SGR 1572. 
en concreto, de nueve días de salario por año de servicios, se encuentra prevista de un modo expreso en el propio contrato de trabajo.

Palabras clave: investigadores, contrato predoctoral, extinción del contrato, indemnización por finalización de contrato, contratos formativos.

Abstract: $\quad$ One of the most contentious issues raised by the predoctoral contract is to determine whether upon its termination the researchers who are party thereto are entitled or not to any compensation. Given that based on Community regulations the provision of compensation for contract termination in these cases is thwarted, the possibility arises of claiming compensation based on national regulations and, in particular Art. 49.1.c) ET, which provides that upon contract termination, except in cases of provisional contracts and training contracts, the worker is entitled to receive compensation equivalent to twelve days' salary per year of service. Now, it is with regard to this point that the judgments of the Asturias High Court of 23 and 30 June 2020 dealt with herein that specifically address this issue are included, with the added peculiarity that, in this case, entitlement to compensation for contract termination, namely, of nine days' salary per year of service, is expressly provided in the actual employment contract.

Keywords: researchers, predoctoral contract, contract termination, compensation for contract termination, training contracts.

\section{Las diferentes vías para dotar de indemnización a la extinción del contrato predoctoral por su cumplimiento}

La principal cuestión litigiosa que ha planteado la extinción del contrato predoctoral por su cumplimiento ha sido, sin lugar a dudas, la de determinar si en estos supuestos el personal investigador predoctoral en formación tiene o no derecho a percibir alguna indemnización. A tal efecto, cabe recordar que nada se prevé al respecto de forma expresa en la Ley 14/2011, de 1 de junio, de la Ciencia, la Tecnología y la Innovación (en adelante, Ley de la Ciencia).

En este contexto, la entrada en vigor del Real Decreto 103/2019, de 1 de marzo, por el que se aprueba el Estatuto del personal investigador predoctoral en formación (en adelante, EPIPF) podía haber supuesto una oportunidad inmejorable para aclarar esa cuestión, sin embargo, pese a lo que cabía esperar, dicha norma no contiene ninguna previsión al respecto, de modo que la misma sigue sin fijar de forma expresa si la extinción del contrato predoctoral por su cumplimiento genera o no el derecho a percibir indemnización alguna ${ }^{1}$. Sin lugar a dudas, este inexplicable silencio ha contribuido a que se haya mantenido la situación de inseguridad jurídica sobre esta materia, con los perjuicios que de la misma se derivan tanto para el personal investigador predoctoral en formación contratado como para las universidades y otros centros de investigación que lo acogen.

En este punto, se han planteado dos vías distintas para dotar de indemnización a los investigadores predoctorales en formación que han visto extinguido su contrato de trabajo por su cumplimiento. En primer lugar, se ha considerado que el derecho a indemnización en estos supuestos podría derivar de la Directiva 1999/70/CE del Consejo, de 28 de junio de 1999, relativa al Acuerdo Marco de la CES, la UNICE y el CEEP sobre el trabajo de duración determinada (en adelante, Directiva 1999/70/CE) y de la jurisprudencia que la interpreta, en la medida que se ha considerado que la situación del personal investigador con contrato predoctoral es comparable a la del personal

\footnotetext{
${ }^{1}$ Un análisis detallado de esta norma en MORENO GENÉ, J., El estatuto del personal investigador predoctoral en formación: aspectos jurídico-laborales y de seguridad social. Barcelona, Atelier, 2020.
} 
con contratos de trabajo por tiempo indefinido y, en consecuencia, debe corresponder a los mismos una indemnización equiparable a la de veinte días de salario por ańo de servicios fijada por el art. 53 ET para la extinción del contrato de trabajo por causas objetivas. En segundo lugar, también se ha considerado que dicha indemnización por la finalización del contrato predoctoral podría derivar del art. 49.1.c) ET, que prevé que, a la finalización del contrato, excepto en los casos del contrato de interinidad y de los contratos formativos, el trabajador tendrá derecho a recibir una indemnización equivalente a doce días de salario por año de servicios.

La primera vía a la que se acaba de hacer referencia, como ya se ha avanzado, se basaba en la posibilidad de que el derecho a una indemnización a la finalización del contrato predoctoral pudiera venir de la mano de la normativa comunitaria y, en particular, de la conocida en su momento como doctrina "de Diego Porras" elaborada por el Tribunal de Justicia de la Unión Europea (en adelante, TJUE), en su sentencia de 14 de septiembre de 2016 (C-596/14, de Diego Porras). A tal efecto, la aplicación por parte de diferentes tribunales laborales de dicha doctrina a una modalidad de contratación específica del ámbito universitario hermana gemela del contrato predoctoral como es el contrato de ayudante de universidad, permitía vislumbrar la posible aplicación de la misma también al contrato predoctoral ${ }^{2}$.

Pese a ello, esta posibilidad no se llegó a concretar nunca respecto a los investigadores predoctorales en formación contratados mediante un contrato predoctoral. En un primer momento, esta posibilidad fue descartada por los tribunales laborales, en particular, por la STSJ del País Vasco, de 15 de mayo de 2018 (Ro. 787/2018) que consideró que no resultaba de aplicación al contrato predoctoral la entonces vigente doctrina "de Diego Porras", puesto que dada la naturaleza formativa que se atribuye a esta modalidad contractual, es muy difícil que se pueda constatar la identidad sustancial entre el trabajador temporal y otro en la misma condición como trabajador fijo que exige dicha doctrina, no en vano, los términos de la comparación de la naturaleza del trabajo, funciones o tareas asignadas y requisitos de formación o cualificación del personal investigador en formación predoctoral difícilmente pueden ser equiparables a las que corresponden a un trabajador fijo, cuya cualificación profesional ya es de doctor.

Recogiendo esta doctrina, la posterior STSJ del País Vasco de 8 de enero de 2019 (Ro. 2325/2018), al conocer de la reclamación de una indemnización por fin de contratación temporal de una investigadora predoctoral en formación en base a la aplicación de la doctrina "de Diego Porras" y aplicando ya la doctrina contenida en las sentencias del TJUE de 5 de junio de 2018 (asuntos C-577/16, Montero Mateos y C-574/16, Norte Facility) y de 21 de noviembre de 2018 (asunto C-619/17, de Diego Porras II), que rectificaba la doctrina "de Diego Porras", indicó que "la extrapolación de la doctrina comunitaria para contratos temporales como los formativos, exige un cuestionamiento eminentemente casuístico que hace difícilmente asimilable dicha doctrina, por cuanto el objeto de la contratación y la relación laboral especial de investigador predoctoral en formación, es la obtención de una cualificación cual es el grado de doctor que hace de difícil enjuiciamiento el término de comparación con un trabajador fijo, que evidentemente ya tendría dicha condición de doctor. Es cierto que pudiera darse el supuesto de casos en que los contratos en prácticas, más difícil en los de formación, supusieran funciones o tareas que pudieran ser idénticas a la del titular fijo, pero ello exigiría un juicio de comparación de la justificación objetiva, con una advertencia de carga de prueba para situaciones comparables y de acreditación que no son de arte menor, y no acontece en el supuesto de autos".

\footnotetext{
${ }^{2}$ Sobre esta cuestión vid. MORENO GENÉ, J., "La aplicación de la doctrina "de Diego Porras" a investigadores y profesores universitarios: extinción de derechos o consolidación de carencias". Revista General del Derecho del Trabajo y de la Seguridad Social, núm. 48, 2018.
} 
A tal efecto, la citada sentencia recuerda que "el derecho a la equiparación indemnizatoria que promueve el principio de no discriminación de la recurrente, exige la identidad sustancial entre el supuesto trabajador temporal y otro en la misma condición como trabajador fijo, que difícilmente acontece en estos contratos de formación predoctoral, máxime cuando el objeto y la finalidad de su contratación es la obtención de este nivel formativo y la titulación de doctor, con sujeción a un plazo máximo que reconoce la normativa universitaria expresada. De ahí, sin perjuicio de la realidad de ámbito de duración limitado y/o con prórrogas, los términos de comparación bajo perspectivas de la naturaleza de trabajo, funciones o tareas asignadas, en requisitos de formación o cualificación, no pueden ser parangonables a los que obtienen en condiciones laborales un fijo cuya cualificación profesional ya está resuelta (doctor). Tampoco podemos olvidar, finalmente, que en el ámbito de la aplicación de la Directiva comunitaria, la cláusula 2.2 del Acuerdo Marco excluiría a los contratos formativos".

Por si ello fuera poco, la aplicación de los efectos de la doctrina "de Diego Porras" a los contratos predoctorales fue desestimada de un modo expreso por el propio TJUE, mediante Auto de 19 de marzo de 2019 (asunto C-293/18, CCOO) en respuesta a una cuestión prejudicial planteada al respecto por el TSJ de Galicia.

A tal efecto, el TJUE recuerda que la cláusula 4.1 del Acuerdo Marco contempla la prohibición de tratar, por lo que respecta a las condiciones de trabajo, a los trabajadores con un contrato de duración determinada de modo menos favorable que a los trabajadores fijos comparables por el mero hecho de tener un contrato de trabajo de duración determinada, a menos que se justifique un trato diferente por razones objetivas.

A partir de estas premisas, el TJUE procede a analizar si en el supuesto enjuiciado nos encontramos ante situaciones comparables. Pues bien, en este punto, aplicando la doctrina ya contenida en sendas sentencias del propio Tribunal de 5 de junio de 2018 (asuntos C-577/16, Montero Mateos y C-574/16, Norte Facility), el Tribunal concluye que "de la definición del concepto de "contrato de duración determinada" que figura en la cláusula 3, punto 1, del Acuerdo Marco se deduce que un contrato de este tipo deja de producir efectos para el futuro cuando vence el término que se le ha asignado, pudiendo constituir dicho término la realización de una obra o servicio determinado, la producción de un hecho o acontecimiento determinado o, como en el caso de autos, una fecha concreta. De este modo, las partes de un contrato de trabajo de duración determinada conocen, desde el momento de su celebración, la fecha o el hecho que determina su término. Este término limita la duración de la relación laboral, sin que las partes deban manifestar su voluntad a este respecto tras la conclusión del contrato (...) En cambio, la extinción de un contrato de trabajo por tiempo indefinido por una de las causas previstas en el art. 52 del Estatuto de los Trabajadores, a iniciativa del empresario, tiene lugar cuando concurren circunstancias que no estaban previstas en el momento de su celebración y que suponen un cambio radical en el desarrollo normal de la relación laboral".

En este contexto, el TJUE considera que el objeto específico de la indemnización por despido establecida en el art. 53.1.b) ET, al igual que el contexto particular en el que se abona dicha indemnización, constituyen una razón objetiva que justifica la diferencia de trato controvertida. A tal efecto, dicha indemnización tiene por objeto compensar el carácter imprevisto de la ruptura de la relación de trabajo por las causas previstas en el art. 52 ET y, por lo tanto, la frustración de las expectativas legítimas que el trabajador podría albergar, en la fecha en que se produce la ruptura, en lo que respecta a la estabilidad en dicha relación laboral.

Por todo ello, el TJUE responde a la cuestión prejudicial planteada indicando que la cláusula 4.1 del Acuerdo Marco debe interpretarse en el sentido de que no se opone a una normativa nacional que no prevé el abono de indemnización alguna a los trabajadores con contratos predocto- 
rales al vencimiento del término por el que estos contratos se celebraron, mientras que se concede indemnización a los trabajadores fijos con motivo de la extinción del contrato de trabajo por una causa objetiva.

En aplicación de esta doctrina del TJUE, la propia STSJ de Galicia de 11 de abril de 2019 ( $\mathrm{R}^{\circ} .34 / 2017$ ) en la que se planteó la cuestión prejudicial o la posterior STSJ de Andalucía (Sevilla) de 8 de julio de 2020 (Ro. 500/2019) han rechazado la pretensión de los investigadores de recibir una indemnización de veinte días de salario por año de servicios en base a la normativa comunitaria.

Frustrada esta posibilidad de dotar de indemnización a los investigadores predoctorales en formación que han visto extinguido su contrato de trabajo por su cumplimiento en base a la normativa comunitaria, aún cabría la posibilidad de reclamar una indemnización en estos supuestos en base a la normativa nacional y, en particular, al art. 49.1.c) ET, que prevé que a la finalización del contrato, excepto en los casos del contrato de interinidad y de los contratos formativos, el trabajador tendrá derecho a recibir una indemnización equivalente a doce días de salario por año de servicios. Pues bien, es en este punto donde se incardinan sendas sentencias del TSJ de Asturias de 23 y de 30 de junio de 2020 (Ro. 129/2020 y 48/2020, respectivamente) objeto de este comentario que abordan específicamente esta cuestión, si bien, con la particularidad añadida de que, en este supuesto, el derecho a percibir una indemnización por finalización del contrato, en concreto, de nueve días de salario por ańo de servicios, se encuentra prevista de un modo expreso en el propio contrato de trabajo.

\section{La doctrina contenida en las SSTSJ de Asturias de 23 y 30 de junio de 2020}

\subsection{Supuesto de hecho y solución de instancia}

Las SSTSJ de Asturias de 23 y 30 de junio de 2020 recogen una relación de hechos probados prácticamente idénticos.

Nos encontramos ante dos investigadoras que son contratadas por un centro de investigación en virtud de un contrato predoctoral para prestar servicios como personal investigador predoctoral en formación dentro de la categoría de titulado superior a jornada completa. En concreto, las investigadoras son contratadas para realizar tareas de investigación en el ámbito de un proyecto específico y novedoso, que contaba con financiación externa. El código de los contratos formalizados era el 420 .

Los contratos se formalizaron con fecha de 7 de enero de 2015 y tenían una duración inicial de un ańo, siendo posteriormente prorrogados en tres ocasiones -el 7 de enero de 2016, el 7 de enero de 2017 y el 7 de enero de 2018-, extendiendo su duración total por un período de cuatro años. A la finalización de la última de las prórrogas se procedió a la extinción de dichos contratos de trabajo por su cumplimiento, sin preverse indemnización alguna en favor de las investigadoras contratadas.

Durante la vigencia del contrato suscrito con sendas investigadoras, en fecha de 3 de marzo de 2017, el Ministerio de Empleo y Seguridad Social decidió en coordinación con el Ministerio de Educación, Cultura y Deportes volver a encuadrar los contratos predoctorales en el epígrafe 401 a efectos del código identificativo del tipo de contrato que se utiliza para la clasificación administrativa, habiéndose comunicado a las mismas que este cambio no afectaba a la naturaleza, derechos y obligaciones de los contratos suscritos en su momento.

Una vez comunicada a las investigadoras la extinción de sus respectivos contratos, las mismas efectuaron una reclamación de indemnización por extinción de contrato siendo ésta expresamente desestimada por la entidad empleadora. Ante esta negativa, las investigadoras presentaron la demanda judicial correspondiente en reclamación de una indemnización por fin de contrato predoctoral equivalente a doce días de salario por año de servicios. 
Las reclamaciones judiciales planteadas fueron resueltas en instancia por el Juzgado de lo Social núm. 5 de Oviedo que desestimó la pretensión de las investigadoras por considerar que las mismas carecían del derecho a percibir indemnización alguna por la finalización de los respectivos contratos predoctorales.

\subsection{El derecho al percibo de la indemnización prevista de forma expresa en las cláusulas del contrato predoctoral formalizado.}

Disconformes las investigadoras con la resolución dictada en instancia plantearon los correspondientes recursos de suplicación que fueron resueltos mediante las SSTSJ de Asturias de 23 y 30 de junio de 2020 ( $R^{\circ}$. 129/2020 y 48/2020, respectivamente) objeto de este comentario en el que reiteraban su derecho al percibo de una indemnización por finalización de los respectivos contratos predoctorales a razón de doce días de salario por año de servicios.

Como fundamento a su petición, las investigadoras alegaron una interpretación y aplicación erróneas de los arts. 11, 15.1.a) y 49.1.c) ET, en relación con lo dispuesto en la Ley de la Ciencia. Como refuerzo a este razonamiento se acude a las propias cláusulas del contrato predoctoral suscrito por sendas investigadoras en las que se establece de forma expresa que a la finalización del contrato el trabajador tendrá derecho a percibir una indemnización equivalente a nueve días de salario por año de servicio (claúsula 8) y que el contrato se regulará, entre otras normas, por lo establecido en el art. 15 ET y en la Ley de la Ciencia.

Asimismo, las investigadoras traen a colación la STSJ de Galicia de 11 de abril de 2019 (Ro. 34/2017) que consideran que contiene un supuesto idéntico y que la Sala de lo Social gallega resolvió considerando que a pesar de la denominación como contratos predoctorales en formación, realmente se trataba de contratos temporales por obra o servicio, que quedaban absolutamente al margen de lo contemplado en el art. 11 ET, correspondiéndoles, por tanto, la indemnización por finalización de contrato prevista en el art. 49.1.c) ET.

Frente a ello, la entidad contratante alega que no corresponde indemnización alguna de acuerdo con la naturaleza formativa propia del contrato predoctoral, indicándose, además, que la sentencia del TSJ de Galicia invocada por las investigadoras no constituye jurisprudencia que deba vincular al TSJ de Asturias.

Frente a estos posicionamientos, como no podía ser de otro modo, el TSJ de Asturias recuerda que la doctrina dictada por otros Tribunales Superiores de Justicia no constituye jurisprudencia y, por tanto, no le vincula a la hora de resolver el fondo del asunto que, a criterio del tribunal, no es otro que la determinación de la naturaleza que cabe atribuir al contrato predoctoral.

En este punto, el TSJ de Asturias acude, ahora sí, a una resolución judicial del Tribunal Supremo, en concreto, la de 6 de noviembre de 2018 (Rº. 222/2017) que, a pesar de declarar la incompetencia de la jurisdicción social en la cuestión planteada, procedió a establecer las características de los contratos predoctorales. A tal efecto, la citada resolución judicial establece lo siguiente: “a) los beneficiarios de las ayudas son estudiantes de doctorado que, estando en posesión del título de grado, estén matriculados en un programa de doctorado de una Universidad española; b) que las ayudas se conceden tras un proceso de selección exigente con arreglo a las bases y directrices de la convocatoria correspondiente (...); c) que el pago de las ayudas se efectúa a los centros de adscripción de los beneficiarios y d) que resulta necesaria la suscripción de un contrato predoctoral previsto y regulado en el artículo 21 de la Ley 14/2011 (...) de naturaleza laboral a celebrar por escrito entre el personal investigador predoctoral en formación, en su condición de trabajador, y la Universidad pública u Organismo de investigación titular de la unidad investigadora, en su condición de em- 
pleador, y deberá acompañarse de escrito de admisión al programa de doctorado expedido por la unidad responsable de dicho programa, o por la escuela de doctorado o posgrado en su caso".

De esta doctrina del Tribunal Supremo, el TSJ de Asturias concluye que es el art. 21 de la Ley de la Ciencia el que regula el contrato predoctoral y que dicha norma no contempla indemnización a la finalización del mismo, y únicamente de forma subsidiaria esta modalidad contractual se regula por lo previsto en el Estatuto de los Trabajadores.

El TSJ de Asturias refuerza esta conclusión acudiendo a su propia doctrina, contenida en su sentencia de 20 de junio de 2019 ( $\mathrm{R}^{\mathrm{o}}$. 14/2019), que declara que este tipo de contratos se integraron en el derecho del trabajo a través de la Ley de la Ciencia, con la introducción de un contrato temporal y a tiempo completo de cuatro años de duración -el contrato predoctoral-, habiéndose convertido esta modalidad contractual en la fórmula jurídica a utilizar desde entonces en todas las convocatorias de ayudas a la formación del personal investigador financiadas con cargo a fondos públicos, en sustitución del modelo 2+2 introducido en su momento por el RD 63/2006, de 27 de enero, por el que se aprueba el Estatuto del Personal Investigador en Formación (en adelante, EPIF).

A tal efecto, se añade en dicha resolución judicial que los sujetos de esta relación laboral son del lado del trabajador, el investigador que estando en posición del Título de licenciado, ingeniero, arquitecto, etcétera, haya sido admitido en un programa de doctorado (art. 21 de la Ley de la Ciencia), y del lado empresarial, se ciñe por la norma a determinados organismos públicos de investigación y a las universidades públicas, si bien, también se abre esta posibilidad a otras entidades de investigación.

Mantiene además la resolución citada que la causa del contrato, es decir, la función económico-jurídica que se persigue a través de dicha contratación, es la finalidad formativa del investigador y el objeto del contrato consiste en el desarrollo de un trabajo de investigación en el ámbito de un proyecto específico y novedoso, que se concreta en la realización de la tesis doctoral y obtención del título de doctor.

Las SSTSJ de Asturias de 23 y 30 de junio de 2020 (Ro. 129/2020 y 48/2020, respectivamente) acuden, además, al más recientemente aprobado Real Decreto 103/2019, de 1 de marzo, por el que se aprueba el Estatuto del Personal Investigador Predoctoral en Formación, que desarrolla y concreta el régimen legal del personal investigador predoctoral en formación previsto por la Ley de la Ciencia y que prevé que dicha modalidad contractual se rige por lo establecido en los artículos 20 y 21 y disposición adicional primera de la Ley de la Ciencia, por el EPIPF y con carácter supletorio por el Estatuto de los Trabajadores, por la demás legislación laboral que le sea de aplicación, por los convenios colectivos y por la voluntad de las partes manifestada en los contratos de trabajo, sin que en ningún caso se puedan establecer en ellos condiciones menos favorables al trabajador o trabajadora o contrarias a las previstas en las disposiciones legales y convenios colectivos antes referidos.

De todo lo expuesto hasta el momento, el TSJ de Asturias obtiene su principal conclusión que no es otra que considerar que "no hay dudas que el contrato suscrito por el actor es un contrato de formación, sometido a la regulación especial de la Ley de la Ciencia, Tecnología e Innovación de 2011, como expresamente consta en la Adenda al contrato de fecha de 3 de marzo de 2017 que dice “(...) ya que dicho (contrato) está regulado como modalidad específica de contratación laboral del personal investigador en formación prevista en el art. 21 de la Ley 14/2011 (...)”.

Aunque el TSJ de Asturias no lo diga de forma expresa, de esta calificación del contrato predoctoral como un contrato formativo parecería desprenderse a priori que el mismo no generaría derecho a indemnización alguna, por no estar prevista en la normativa específica de esta modalidad contractual ni poder desprenderse la misma de la aplicación subsidiaria del art. 49.1.c) ET, puesto que en el mismo se excluye de forma expresa la previsión de indemnización para los supuestos de contratos formativos, a los cuales se asimila al contrato predoctoral. 
Bajo estas premisas, sin embargo, el Tribunal pone de manifiesto que en el clausurado del respectivo contrato predoctoral formalizado por cada una de las investigadoras se prevé de forma expresa una indemnización para la finalización del mismo de nueve días de salario por cada año de servicio o la establecida en la norma específica que sea de aplicación y, en consecuencia, éste deberá ser el importe mínimo con el que deberá indemnizarse a cada una de las investigadoras. Por el contrario, las mismas no tendrán derecho a percibir, tal como solicitaban, una indemnización equivalente a doce días de salario por ańo de servicios, en base a que se trata de un contrato por obra o servicio determinado o en base a la cláusula 8 del contrato, puesto que como ya se ha indicado, el derecho al percibo de la indemnización por la finalización del contrato no se deriva de la equiparación del contrato predoctoral a un contrato para obra o servicio determinados, sino únicamente de su previsión expresa en el clausulado del contrato y, por tanto, su cuantía no puede ser otra que los nueve días de salario por año de servicios previstos de forma expresa en el mismo.

De forma coherente con los razonamientos expuestos, el TSJ de Asturias termina condenando a la entidad contratante de las dos investigadoras a abonar a las mismas una indemnización por finalización del contrato equivalente a nueve días de salario por año trabajado.

\section{3. ¿En qué supuestos la finalización del contrato predoctoral por su cumplimiento puede dar derecho a indemnización y en qué cuantía?}

Ante la ausencia de previsión expresa en la Ley de la Ciencia y en el EPIPF, la respuesta a la cuestión de si la indemnización por la finalización del contrato predoctoral puede derivar del art. 49.1.c) ET se ha hecho depender de la naturaleza jurídica que se asigna al contrato predoctoral, de modo que aquellos que asimilan esta modalidad contractual a un contrato para obra o servicio determinados mantienen que a su finalización el investigador tendría derecho a la indemnización prevista para esta modalidad contractual -doce días de salario por año de servicios- ${ }^{3}$, mientras que quienes la asimilan a un contrato formativo, consideran que en estos supuestos el derecho a indemnización no se encuentra contempladó.

A tal efecto, desde que la Ley de la Ciencia introdujera el contrato predoctoral como modalidad contractual dirigida a la contratación de los investigadores predoctorales en formación se ha suscitado un interesante debate sobre su naturaleza jurídica, que ha basculado, básicamente, entre quienes mantienen que se trata de una modalidad contractual formativa, próxima al contrato en prácticas, y los que consideran que se trata de una modalidad de contrato para obra o servicio determinados, cuyo objeto sería la elaboración y defensa de la tesis doctoral5.

\footnotetext{
${ }^{3}$ En esta dirección se encuentra REQUENA MONTES, O., "Aproximación crítica al Estatuto del Personal Investigador Predoctoral en Formación”. Revista General del Derecho del Trabajo y de la Seguridad Social, núm. 53, 2019, pág. 391.

${ }^{4}$ En esta última dirección encontramos, entre otros, a GONZÁLEZ ORTEGA, S., "El régimen jurídico del personal del SUE y del SECTI a estudio: modalidades contractuales y categorías profesionales en el ámbito del SUE y del SECTI", En AAVV, Disquisiciones jurídicas sobre el ámbito universitario. Cizur Menor (Navarra), Thomson-Reuters Aranzadi, 2016, pág. 150, GONZÁLEZ DEL REY RODRÍGUEZ, I., "La contratación de investigadores por universidades públicas en la Ley de la Ciencia de 2011". Revista de Trabajo y Seguridad Social. CEF, núm. 404, 2016, pág. 54 o MOLINA NAVARRETE, C, "Empleo público temporal y estabilidad obligacional: la indemnización por fin de contrato o de nombramiento", En CARO MUNOZZ, A.I (Dira.) y ROMERO BURILLO, A.M. y BELLO PAREDES, S. (Coords.), La articulación de la gestión universitaria a debate. Cizur Menor (Navarra), Thomson Reuters - Aranzadi, 2018, pág. 120.

${ }^{5}$ Este de por si complejo debate en torno a la naturaleza jurídica del contrato predoctoral se vio, además, especialmente reactivado por un cúmulo de desafortunadas actuaciones de la Administración de la Seguridad Social a la hora de fijar el código de contrato aplicable a dicha modalidad contractual. El primer desatino consistió en no establecer un código específico para la misma, fijándose al respecto el código 401, correspondiente al contrato para obra o servicio determinados. Con la voluntad de enmendar este primer desatino, se cometió otro no menor, procediendo la Administración de la Seguridad Social a alterar de una manera unilateral y con carácter retroactivo dicho código de contrato, pasando a asignar a partir de este momento el código de contrato 420, propio del
} 
Recuérdese al respecto que la Ley de la Ciencia procedió a sustituir la contratación en prácticas del personal investigador en formación prevista hasta el momento por el anterior EPIF, por la contratación de dicho colectivo mediante el nuevo contrato predoctoral, el cual, aunque indudablemente comparte diversos de los elementos básicos y esenciales que definen al contrato en prácticas, formalmente se configura como una modalidad contractual específica y diferenciada de dicho contrato formativo, que responde a unos objetivos distintos y sigue una dinámica propia. Pese a ello, no cabe duda que el contrato predoctoral y el contrato en prácticas siguen compartiendo una indudable finalidad formativa, como lo indica el hecho de que los investigadores contratados mediante esta modalidad contractual sean denominados como personal investigador predoctoral en formación.

Este ha sido precisamente el criterio adoptado, entre otras, por la STSJ del País Vasco de 15 de mayo de 2018 (Ro. 787/2018), que abordó por primera vez en sede judicial la naturaleza jurídica que cabe atribuir al contrato predoctoral, así como los importantes efectos jurídicos que de la misma se derivan en materia indemnizatoria, concluyendo al respecto que nos encontramos ante una relación laboral/contrato especial para tareas de investigación en un proyecto específico, pero con una finalidad evidentemente formativa ${ }^{6}$. En otras palabras, en la citada resolución judicial se considera que no nos encontramos propiamente ni ante un contrato para obra o servicio determinados ni ante un contrato en prácticas, sino ante una modalidad contractual especial del ámbito de la investigación, pero que, por su finalidad, consistente en la formación predoctoral hasta la obtención del título de doctor, tiene un carácter formativo. Esta apreciación permite afirmar al tribunal que el contrato predoctoral debe quedar asimilado más a un contrato formativo que a un contrato para obra o servicio determinados ${ }^{7}$.

Esta configuración de la naturaleza jurídica del contrato predoctoral, como no podía ser de otro modo, predetermina el resto de razonamientos de la citada resolución judicial. A tal efecto, no se reconoce al investigador en formación derecho a percibir indemnización alguna tras la finalización del contrato predoctoral, puesto que la misma no se prevé de un modo expreso en la Ley de la Ciencia, ni tampoco puede extenderse a esta modalidad contractual la prevista para el contrato para obra o servicio determinados puesto que no se trata de un contrato asimilable. Además, por si fuera poco, el contrato en prácticas al que el contrato predoctoral se podría asimilar en mayor medida tampoco prevé indemnización alguna tras la finalización del contrato.

Puede compartirse con esta resolución judicial que el contrato predoctoral se configura como una modalidad contractual específica del ámbito de la investigación, distinta a cualquiera de las contempladas en el Estatuto de los Trabajadores. Es cierto, también, que dicho contrato persigue una finalidad formativa, consistente en la formación del investigador predoctoral que normalmente debe concluir con la elaboración de la tesis doctoral y la obtención del título de Doctorado. La suma de ambas consideraciones permite llegar, a su vez, a la conclusión de que los investigadores predoctorales en formación contratados mediante esta modalidad contractual no tienen derecho a indemnización alguna a la finalización de su vínculo contractual ${ }^{8}$. Por lo demás, esta conclusión no

contrato en prácticas. Finalmente, ante las airadas quejas de los afectados, se optó por volver a la situación inicial, asignando nuevamente al contrato predoctoral el código de contrato 401, correspondiente al contrato por obra o servicio determinados. Aunque como señala la STSJ del País Vasco de 15 de mayo de 2018 (Ro. 787/2018) el código de contrato que asigne la Administración de la Seguridad Social al contrato predoctoral no altera en modo alguno su naturaleza jurídica, los vaivenes sufridos al respecto han contribuido a generar grandes dudas sobre la naturaleza jurídica que cabe atribuir a esta modalidad contractual. Sobre estas inquietudes vid. LÓPEZ INSUUA, B.M., "La precarización del personal investigador en formación de nuevo en el ojo del huracán: anomalía jurídica en la "codificación" de los contratos predoctorales". Derecho de las Relaciones Laborales, núm. 7, 2017, págs. 417 y ss.

${ }^{6}$ Un comentario de esta resolución judicial en MORENO GENÉ, J., "La ambigua naturaleza jurídica del contrato predoctoral y su incidencia a efectos indemnizatorios. Comentario a la STSJ del País Vasco 1064/2018, de 15 de mayo". Revista de Trabajo y Seguridad Social. CEF, núm. 43, 2019, págs. 160 a 168.

${ }^{7}$ Vid. MORENO GENÉ, J., "La ambigua naturaleza jurídica del contrato predoctoral...” cit.

${ }^{8}$ Las Salas de lo Social de otros Tribunales Superiores de Justicia también llegan a esta misma conclusión. Así, por ejemplo, la STSJ de Madrid de 21 de enero de 2019 (Ro. 806/2018) concluye que tratándose el contrato predoctoral "de un contrato formativo, 
se opone a la finalidad perseguida por la introducción de una indemnización a la finalización de determinados contratos temporales, que no era otra que la de desincentivar en cierto modo el recurso a estas modalidades temporales más utilizadas y con un mayor nivel de fraude en su empleo, en especial, el contrato para obra o servicio determinados. A tal efecto, con carácter general, el recurso al contrato predoctoral por parte de universidades y otros centros de investigación se ajusta plenamente a la legalidad y no se acude al mismo, por tanto, de un modo fraudulento.

Pese a ello, aún puede cuestionarse si de estas premisas cabe deducir de un modo inexorable que los investigadores predoctorales en formación contratados mediante esta modalidad contractual no tienen derecho a indemnización alguna a la finalización de su vínculo contractual. A tal efecto, cabe recordar que el contrato predoctoral, en tanto que modalidad específica del ámbito de la investigación, se rige por su normativa específica, recogida en la Ley de la Ciencia. Si acudimos a esta norma, se observa que la misma no contiene ninguna previsión relativa a la existencia de indemnización por finalización del contrato. De esta ausencia se pueden deducir dos conclusiones alternativas: la primera, que con dicha ausencia se está previendo que la extinción de esta modalidad contractual por su cumplimiento no da derecho a indemnización alguna; y, la segunda, que esta materia no está contemplada de forma expresa en dicha norma y que, por tanto, debe acudirse a la regulación supletoria prevista por la misma. A tal efecto, como ya se ha indicado a lo largo de este trabajo, el art. 20 de la Ley de la Ciencia establece que, en lo no regulado en dicha norma, será de aplicación lo dispuesto en el ET y sus normas de desarrollo. Este sistema de fuentes reguladoras del contrato predoctoral se ha visto desarrollado, a su vez, por el EPIPF, cuyo art. 3 establece que dicha modalidad contractual "se rige (...) con carácter supletorio, por el texto refundido de la Ley del Estatuto de los Trabajadores (...), por la demás legislación laboral que le sea de aplicación, por los convenios colectivos y por la voluntad de las partes manifestada en los contratos de trabajo, sin que en ningún caso se puedan establecer en ellos condiciones menos favorables al trabajador o trabajadora o contrarias a las previstas en las disposiciones legales y convenios colectivos antes referidos".

Es, precisamente, en esta segunda opción donde se plantea de nuevo la controversia, puesto que si se aplica supletoriamente a la extinción por cumplimiento del contrato predoctoral la regulación prevista en el art. 49.1.c) ET, podría corresponder a los investigadores predoctorales en formación una indemnización equivalente a doce días de salario por cada año de servicio, salvo que se considere que dicha modalidad contractual queda incluida entre los contratos formativos, a los que dicho precepto exceptúa del derecho a dicha indemnización. Como ya se ha indicado, esta última es la opción que adopta la STSJ del País Vasco de 15 de mayo de 2018 (Ro. 787/2018) al considerar que al contrato predoctoral, dada su naturaleza formativa, le resulta de aplicación esta excepción?

Sin lugar a dudas, la previsión de una clave específica de contrato que se prevé en el EPIPF para el contrato predoctoral, distinta a la compartida hasta el momento con el contrato para obra o servicio determinados, va a ahondar en esta conclusión. A tal efecto, el modelo previsto de contrato predoctoral por el servicio público de empleo estatal, al tiempo que asigna a este contrato el código de contrato 404, distinto, por tanto, al contrato para obra o servicio determinado y al contrato en prácticas, establece que al contrato predoctoral no le será de aplicación la disposición transitoria octava del Estatuto de los Trabajadores que es, precisamente, la que fija la indemnización correspondiente por finalización de contrato temporal.

\footnotetext{
opera la cláusula de exclusión del art. 49.1.c) del ET y por ello no se genera derecho a indemnización por finalización de contrato”. En parecidos términos, vid. también, la STSJ de Andalucía (Sevilla) de 8 de julio de 2020 (Ro. 500/2019)

${ }_{9}^{9}$ BALLESTER LAGUNA, F., "El nuevo Estatuto del personal investigador predoctoral en formación: un "traje a medida" del contrato predoctoral”. Revista Española de Derecho del Trabajo, núm. 220, 2019, también se inclina sobre esta interpretación. Sin perjuicio de que el autor considera que no se puede dar una respuesta categórica a esta cuestión en tanto que existe una regla general favorable al derecho indemnizatorio y ello se compadece mal con una interpretación extensiva de las excepciones excluyentes del derecho.
} 
Frente a la posición mantenida por la STSJ del País Vasco de 15 de mayo de 2018 (Ro. 787/2018), encontramos la STSJ de Galicia de 11 de abril de 2019 (Ro. 34/2017), la cual, aunque con una argumentación muy sucinta, considera que "el art. 49.1.c) ET incluye dentro de su ámbito a toda contratación temporal, de las reguladas en el artículo 15 del Estatuto de los Trabajadores, únicas posibles en la legislación laboral, es decir, obra o servicio, eventual, e interinidad, excluyendo de tal efecto a éste último y además al formativo del art. 11, contrato que en modo alguno puede equipararse al suscrito por los trabajadores afectados por el conflicto aun cuando se denomine predoctoral en formación". A lo que añade que el contrato formativo "únicamente cabe a través de la normativa regulada en el artículo 11, que en modo alguno se cumple con el que ahora se discute" ${ }^{\text {. }}$.

En base a estas consideraciones, el TSJ de Galicia concluye que los contratos predoctorales formalizados por los investigadores predoctorales en formación han de calificarse como temporales de obra o servicio y, por tanto, a su finalización dar lugar al derecho a percibir la indemnización prevista en el art. 49.1.c) ET para esta tipología de contrato ${ }^{11}$.

En definitiva, el debate sobre esta cuestión radica en determinar si el contrato predoctoral puede incluirse o no entre los contratos formativos a los que el art. 49.1.c) ET priva de indemnización a su cumplimiento ${ }^{12}$. A tal efecto, utilizando una interpretación más teleológica, el TSJ del País Vasco ha considerado que el contrato predoctoral sí quedaría incluido en esta categoría de contratos formativos, mientras que, de conformidad con una interpretación más formal, el TSJ de Galicia ha considerado que dicha asimilación no sería posible, por considerar que esta modalidad contractual se encuentra más próxima al contrato para obra o servicio determinados.

Como fácilmente puede apreciarse, las soluciones dispensadas a la cuestión planteada por la STSJ de Galicia de 11 de abril de 2019 (Ro. 34/2017) y por la STSJ del País Vasco de 15 de mayo de 2018 (Ro. 2976/2015) son diametralmente opuestas, de modo que la respuesta definitiva a dicha cuestión quedaba a expensas de lo que decidiera, en su momento, el Tribunal Supremo sobre esta cuestión.

La respuesta del Tribunal Supremo al dilema suscitado ha llegado en su sentencia de 13 de octubre de 2020 (Ro. 119/2019) $)^{13}$, que ha venido a alinearse en lo esencial con la doctrina dictada por la Sala de lo Social del TSJ del País Vasco. A tal efecto, el Tribunal Supremo constata que la normativa reguladora del contrato predoctoral no ha previsto ninguna indemnización específica a su extinción y tampoco ha efectuado una remisión expresa al Estatuto de los Trabajadores en este punto. A partir de estas premisas, mantiene que para poderse activar la supletoriedad de la regulación del Estatuto de los Trabajadores, expresamente prevista en el art. 20 de la Ley 14/2011, se hace necesario delimitar la calificación del contrato en relación con las modalidades que se diseñan en dicho texto legal, en tanto que en el Estatuto de los Trabajadores, no toda finalización de un contrato de duración temporal lleva aparejado el derecho a una indemnización.

\footnotetext{
${ }^{10}$ Un comentario de esta resolución en MORENO GENÉ, J., "La naturaleza jurídica y efectos indemnizatorios del contrato predoctoral: el debate continúa: Comentario a la Sentencia del Tribunal Superior de Justicia de Galicia de 11 de abril de 2019”. Revista de Trabajo y Seguridad Social. CEF, núm. 436, 2019, págs. 111 a 118.

${ }^{11}$ En la misma dirección, REQUENA MONTES, O., "Aproximación crítica...” cit. pág. 391, indica que "en el contrato predoctoral es la tesis doctoral la que constituye la "obra" -científica- que da lugar a la celebración del contrato, como pudiera serlo cualquier otra obra en el marco del contrato para obra o servicio determinado. De modo que, si la extinción de esta modalidad contractual viene acompańada de una indemnización de doce días por año de servicio prestado, la misma cantidad correspondería a quien ve extinguido su contrato predoctoral, puesto que su normativa específica guarda silencio al respecto y continúa delegando en el ET al fin de completar aquello que no prevé el EPIPF".

${ }^{12}$ En parecidos términos, BALLESTER LAGUNA, F., "El nuevo Estatuto del personal investigador...” cit. indica que la respuesta a la cuestión planteada dependerá de la interpretación restrictiva o amplia sobre cuáles son los contratos formativos a los que se refiere el art. 49.1.c) ET, si únicamente los contratos formativos así denominados y regulados en el propio Estatuto de los Trabajadores o cualquier otro contrato de naturaleza formativa, como es el contrato predoctoral.

${ }^{13}$ Un comentario de esta sentencia en MORENO GENÉ, J., "La indemnización por finalización del contrato predoctoral. Fin del debate: Comentario a la Sentencia del Tribunal Supremo 903/2020, de 13 de octubre”. Revista de Trabajo y Seguridad Social. CEF, núm. 454, 2021, págs. 154 a 163.
} 
En este punto, el Alto Tribunal considera que si se pretenden buscar analogías entre el contrato predoctoral y las modalidades contractuales a las que se refiere el art. 49.1.c) ET, "se hace verdaderamente difícil acudir al contrato para obra y servicio determinado y, por el contrario, sería el contrato en prácticas del art. 11 ET el que presentaría mayores similitudes- de manera muy particular, la finalidad explícita de la contratación-", lo cual permite concluir al Tribunal Supremo que "el legislador ha diseñado una modalidad contractual, de carácter formativo, a la que no ha atribuido indemnización en el momento de su finalización, en la misma línea seguida con otros contratos temporales del ET".

Pues bien, las SSTSJ de Asturias de 23 y de 30 de junio de 2020 (Ro. 129/2020 y 48/2020, respectivamente) objeto de este comentario se alinean claramente con la posición adoptada en un primer momento por el TSJ del País Vasco y ahora también por el Tribunal Supremo, habiéndose desechado, por el contrario, la opción adoptada por el TSJ de Galicia, cuya doctrina había sido alegada precisamente por las investigadoras en formación para reclamar su derecho a una indemnización de doce días de salario por año de servicios a la finalización de sus respectivos contratos predoctorales. En este punto, ya se ha indicado que el TSJ de Asturias concluye afirmando de modo muy contundente que "no hay dudas que el contrato suscrito por el actor es un contrato de formación".

Y, aunque el TSJ de Asturias no lo diga de forma expresa, de esta calificación del contrato predoctoral como un contrato que se asimila a los contratos formativos se obtendría la conclusión de que el mismo no generaría derecho a indemnización alguna, por no estar prevista en la normativa específica del contrato predoctoral ni poder desprenderse la misma de la aplicación subsidiaria del art. 49.1.c) ET, puesto que dicho precepto no sería aplicable subsidiariamente en materia de indemnización y, en todo caso, en el mismo se excluye de forma expresa la previsión de indemnización para los supuestos de contratos formativos, a los cuales se asimila el contrato predoctoral.

Ahora bien, a pesar de todo lo indicado, las SSTSJ de Asturias de 23 y 30 de junio de 2020 (Ro. 129/2020 y 48/2020, respectivamente) finalmente sí acaban estimando parcialmente el recurso planteado por las investigadoras vinculadas mediante un contrato predoctoral, de modo que terminan concediendo a las mismas una indemnización por finalización de sus respectivos contratos equivalente a nueve días de salario por año de servicios. En este punto, cabe preguntarse si ello supone una contradicción con todo lo expuesto hasta el momento.

La respuesta a la cuestión planteada no puede ser más que negativa, no en vano, el derecho a la percepción de una indemnización a la finalización del contrato predoctoral, además de poder venir impuesta por la ley, lo cual, como se acaba de exponer, es de muy difícil justificación cuando nos referimos a los contratos predoctorales, también puede derivar del propio clausurado de los contratos suscritos, no en vano, en el supuesto enjuiciado, el derecho a indemnización a la finalización del contrato sí se encontraba previsto de forma expresa. Recuérdese al respecto que, para llegar a su decisión definitiva, el Tribunal constata que en el clausurado del respectivo contrato predoctoral formalizado por cada una de las investigadoras se prevé de forma expresa una indemnización para la finalización del mismo de nueve días de salario por cada año de servicio o la establecida en la norma específica que sea de aplicación y, en consecuencia, éste deberá ser el importe mínimo con el que deberá indemnizarse a cada una de las investigadoras.

La conclusión obtenida por el TSJ de Asturias parece acertada si tenemos en cuenta que puede entenderse que la previsión expresa recogida en el clausurado del contrato predoctoral del derecho a percibir una indemnización a su finalización constituiría una especie de condición más beneficiosa, cuyo cumplimiento estaría protegido de forma efectiva por "el principio jurídico de confianza legítima, así como el de buena fe" ${ }^{\prime 4}$.

${ }^{14}$ Vid. MOLINA NAVARRETE, C., "Empleo público temporal y estabilidad obligacional...” cit. pág. 125. 
Esta circunstancia justificaría, además, que la indemnización finalmente percibida por las investigadoras haya sido únicamente de nueve días de salario por ańo de servicios y no de doce como las mismas reclamaban, no en vano, a éstas no se les reconoce el derecho a recibir una indemnización en base a lo previsto por el art. 49.1.c) ET, que, por la fecha de formalización de los correspondientes contratos de trabajo - 7 de enero de 2015- sería equivalente a doce días de salario por año de servicios ${ }^{15}$, sino exclusivamente por venir prevista de forma expresa en las cláusulas de sus respectivos contratos, -cláusula 8-, a razón de nueve días de salario por ańo de servicios ${ }^{16}$.

Con toda probabilidad, esta reclamación hubiera recibido una solución distinta si en la correspondiente cláusula del contrato predoctoral formalizado por ambas investigadoras no se hubiera fijado una indemnización específica, sino que se hubiera previsto que la misma sería la contemplada en el Estatuto de los Trabajadoras para alguna otra modalidad contractual, en particular, para el contrato para obra o servicio determinados, puesto que en este caso, la indemnización a percibir hubiera sido la correspondiente a esta modalidad contractual, que dada la fecha de formalización del contrato predoctoral -7 de enero de 2015- se hubiera elevado hasta los doce días de salario por año de servicios.

En definitiva, como acertadamente se ha seńalado, en caso de preverse en el contrato predoctoral de forma expresa el derecho a percibir alguna indemnización, debe estarse a esta previsión contractual, de modo que si se prevé una cantidad específica habría que primar esta, y si, en cambio, se remite a la normativa reguladora del Estatuto de los Trabajadores, habrá que estar a lo previsto por el art. 49.1.c) $\mathrm{ET}^{17}$.

Pese a ello, en estos supuestos aún podrían plantearse serias dudas sobre la validez de dichas cláusulas, no en vano, al tratarse las entidades contratantes de los investigadores predoctorales en formación normalmente de administraciones públicas - universidades y organismos públicos de investigación, entre otros-, la posibilidad de incorporar condiciones más beneficiosas se encuentra especialmente restringida por el cumplimiento de los principios de legalidad y de igualdad ${ }^{18}$.

Recuérdese en este punto el criterio un tanto restrictivo mantenido al respecto por el Tribunal Supremo tras la sentencia de 13 de julio de 2017 (Ro. 2976/2015) que, a pesar de seguir admitiendo que se puedan generar condiciones más beneficiosas en el seno de las relaciones laborales con la administración pública, corrige su doctrina anterior sobre esta materia, pasándose a exigir nuevos requisitos que, a criterio del propio Tribunal hacen más "dificultosa -excepcional, más bien- la posibilidad de adquirir una condición más beneficiosa frente a la Administración empleadora"19.

A tal efecto, el Tribunal Supremo mantiene que, "si bien tratándose de un empresario privado el reconocimiento de una condición más beneficiosa no tiene más límite que el que en su caso pueda representar el respeto a la Constitución y a la ley, cuando se trata de administraciones públicas ese obligado acatamiento del principio de legalidad -en sentido amplio- se cualifica con el sobreańadido sometimiento a los específicos principios de competencia, de igualdad y presupuestario, que excluyen la posible obtención de condición más beneficiosa cuando la misma se oponga a norma legal de derecho necesario o prohibición expresa de convenio colectivo, o cuando -por parte empresarial- se carezca de la debida competencia para atribuirla" ${ }^{20}$.

\footnotetext{
${ }^{15}$ Recuérdese al respecto que, de conformidad con la disposición transitoria octava del Estatuto de los Trabajadores, a los contratos temporales celebrados a partir del 1 de enero de 2015 que les corresponda la indemnización prevista por finalización del contrato del art. 49.1.c) ET, la misma ascenderá a doce días de salario por cada año de servicio.

${ }^{16}$ De conformidad con la disposición transitoria octava del Estatuto de los Trabajadores, la indemnización de nueve días por año de servicio sería la correspondiente a los contratos temporales formalizados durante el año 2012.

${ }^{17}$ Vid. MOLINA NAVARRETE, C., "Empleo público temporal y estabilidad obligacional...” cit. pág. 126.

${ }^{18}$ Vid. MOLINA NAVARRETE, C., "Empleo público temporal y estabilidad obligacional...” cit. pág. 126.

${ }^{19}$ Vid también, el interesante voto particular que se contiene en la sentencia que formulan diferentes magistrados.

${ }^{20}$ Vid. sobre esta sentencia, CANO GALÁN, Y., "Cambio jurisprudencial en relación con el reconocimiento de condiciones más beneficiosas en el ámbito de la Administración Pública”. Diario la Ley, no 9080, 2017.
} 
En definitiva, sumando las exigencias tradicionales y las incorporadas posteriormente por el Tribunal Supremo, la posibilidad de adquirir una condición más beneficiosa en el marco de la relación laboral con las administraciones públicas se subordina actualmente a una triple exigencia: a) que traiga origen en voluntad inequívoca del empleador; b) que la misma sea directamente atribuible al órgano que ostente adecuada competencia para vincular a la correspondiente Administración; y c) que se trate de un beneficio "paeter legem", en tanto que no contemplado ni prohibido -de forma expresa o implícita- por disposición legal o convencional algunas de las que predicar su imperatividad como Derecho necesario absoluto.

El análisis de estas exigencias en el supuesto enjuiciado nos plantea un problema ya de partida, no en vano, plantea serias dudas que la introducción de esta condición más beneficiosa, consistente en la previsión de una indemnización a la finalización del contrato predoctoral, tenga su origen en la voluntad inequívoca de los empleadores, es decir, de las universidades y otros centros de investigación públicos, de añadir este derecho al catálogo de derechos reconocidos al personal investigador predoctoral en formación contratado. Más bien, parece que la previsión de estas indemnizaciones en los contratos predoctorales se debió al desconcierto que planteó en su momento la aprobación y entrada en vigor del contrato predoctoral. En este punto, cabe recordar el cúmulo de desafortunadas actuaciones de la Administración de la Seguridad Social a la hora de fijar el código de contrato aplicable a dicha modalidad contractual, de modo que, en un primer momento, se fijó como código específico para este contrato el 401, correspondiente al contrato para obra o servicio determinados ${ }^{21}$. Probablemente esta circunstancia motivó que en los modelos de algunos contratos predoctorales que se formalizaron se incluyera el derecho al percibo de una indemnización a la finalización de los mismos, en los mismos o en parecidos términos que se preveía para los contratos para obra o servicio determinados que se formalizaban en las mismas universidades y otros centros de investigación públicos. En otros términos, la introducción de la previsión de una indemnización a la finalización del contrato predoctoral podría deberse más a un error de interpretación de la norma que a una voluntad inequívoca de universidades y otros centros de investigación públicos de incorporar esta condición más beneficiosa en los contratos suscritos.

Con toda probabilidad, el hecho de que tras la aprobación del EPIPF, el modelo previsto de contrato predoctoral por el servicio público de empleo estatal, al tiempo que asigna a este contrato el código de contrato 404, distinto, por tanto, al contrato para obra o servicio determinados y al contrato en prácticas, establezca que al contrato predoctoral no le será de aplicación la disposición transitoria octava del Estatuto de los Trabajadores que es, precisamente, la que fija la indemnización correspondiente por finalización de contrato temporal, comportará que de facto deje de introducirse en estos contratos la condición más beneficiosa consistente en la previsión de una indemnización a su finalización.

Por lo demás, también cabría plantearse las implicaciones que desde el punto de vista del principio de igualdad podría tener el hecho de que a unos investigadores se les reconozca de forma expresa en sus contratos predoctorales una indemnización por finalización del contrato predoctoral y, por tanto, tengan derecho a la misma, mientras que otros investigadores también predoctorales, de la misma universidad u organismo de investigación, no tengan previsto en su contrato este derecho y, por tanto, queden excluidos del derecho a percibir la referida indemnización.

Ninguna de estas cuestiones de validez de la condición más beneficiosa introducida en los respectivos contratos predoctorales formalizados con las investigadoras, consistente en la previsión

\footnotetext{
${ }^{21}$ Recuérdese, en todo caso, que, con la voluntad de enmendar este primer desatino, se cometió otro no menor, procediendo la Administración de la Seguridad Social a alterar de una manera unilateral y con carácter retroactivo dicho código de contrato, pasando a asignar a partir de este momento el código de contrato 420, propio del contrato en prácticas. Posteriormente, ante las airadas quejas de los afectados, se optó por volver a la situación inicial, asignando nuevamente al contrato predoctoral el código de contrato 401, correspondiente al contrato por obra o servicio determinados.
} 
de una indemnización a la finalización del contrato, se han suscitado por las SSTSJ de Asturias de 23 y 30 de junio de 2020 (Ro. 129/2020 y 48/2020, respectivamente) objeto de este comentario, que no han dudado, por tanto, en ningún momento de la legalidad y validez de las mismas.

Para concluir cabe indicar que, a pesar de que con el actual marco normativo se excluye el derecho al percibo de una indemnización a la finalización del contrato predoctoral por su cumplimiento, salvo que, como sucede en el supuesto enjuiciado por las SSTSJ de Asturias de 23 y 30 de junio de 2020 objeto de este comentario, dicha posibilidad se encuentre prevista de forma expresa en el clausurado del contrato de trabajo, no cabe duda que nos encontramos ante una cuestión ciertamente controvertida, que hace del todo necesario que se abra una reflexión sobre la conveniencia o no de que la extinción del contrato predoctoral por su cumplimiento comporte el derecho a una indemnización y, en su caso, en qué cuantía.

En este punto, sería conveniente que se procediera a dignificar las condiciones laborales del personal investigador predoctoral en formación. A tal efecto, la exclusión del derecho a percibir una indemnización a la finalización del contrato predoctoral constituye una de las principales disfunciones de esta modalidad contractual ${ }^{22}$, lo que hace del todo necesaria una intervención del legislador dirigida a paliar esta anomalía, previéndose al respecto, de un modo expreso, el derecho a percibir una indemnización a la finalización del contrato predoctoral por su cumplimiento en cuantía, cuanto menos, equivalente a la prevista para la finalización de otros contratos temporales - v.gr. contrato para obra o servicio determinados-. Meras razones de política científica y de equidad justificarían por si mismas la incorporación de una indemnización en estos supuestos.

A falta de esta conveniente intervención legislativa, aún podría plantearse si por vía de la negociación colectiva desarrollada en el marco de las universidades y otros centros de investigación podría introducirse el derecho a que los investigadores predoctorales en formación percibieran alguna indemnización a la finalización de sus contratos predoctorales, no en vano, aunque la Ley de la Ciencia y el EPIPF en formación no contemplen el derecho a una indemnización en estos supuestos, tampoco se oponen expresamente a la misma. Sin embargo, no parece que esta pueda ser una vía sencilla de incorporación de estos derechos indemnizatorios, dado el tradicional desinterés de la negociación colectiva desarrollada en el marco de las universidades y otros centros de investigación por regular las condiciones de trabajo de este colectivo de investigadores en formación. A tal efecto, aunque haya algún convenio colectivo que pueda incluir en su ámbito de aplicación a dicho colectivo de investigadores, lo más habitual es que, o bien, los excluyan o que únicamente prevean su aplicación a los mismos de forma subsidiaria o supletoria a lo dispuesto en los programas y convocatorias de ayudas a la investigación con los que se financia el contrato de trabajo del investigador predoctoral en formación, de modo que si en dichos programas y convocatorias de ayudas a la investigación no se recoge la previsión de una indemnización por finalización del contrato predoctoral, difícilmente la misma se incorporará por vía de la negociación colectiva puesto que la misma debería ser financiada directamente por las universidades y otros centros de investigación de recepción de este colectivo de investigadores ${ }^{23}$.

${ }^{22}$ Desgraciadamente no es esta la única disfunción que acompaña al contrato predoctoral, véase a título de ejemplo, las que provoca en materia retributiva. Vid. sobre esta cuestión, BALLESTER LAGUNA, F., "Claroscuros en la regulación del salario aplicable al contrato predoctoral". Comentario a la Sentencia del Tribunal Supremo, Sala de lo Contencioso-Administrativo, 642/2020, de 3 de junio". Revista de Trabajo y Seguridad Social. CEF, núm. 449-450.

${ }^{23}$ Sobre esta materia vid. MORENO GENÉ, J., "El tratamiento del "personal investigador contratado" en la negociación colectiva de las universidades". Aranzadi Social, núm. 9, 2007. Vid. también, MORENO GENÉ, J., "Balance de diez años de negociación colectiva del PDI laboral en las Universidades Públicas", En XI y XII Seminarios sobre aspectos jurídicos de la gestión universitaria. Thomson-Reuters Aranzadi, Cizur Menor (Navarra), 2018. 


\section{Bibliografía}

BALLESTER LAGUNA, F., "El nuevo Estatuto del personal investigador predoctoral en formación: un "traje a medida" del contrato predoctoral". Revista Española de Derecho del Trabajo, núm. 220, 2019.

BALLESTER LAGUNA, F., "Claroscuros en la regulación del salario aplicable al contrato predoctoral". Comentario a la Sentencia del Tribunal Supremo, Sala de lo Contencioso-Administrativo, 642/2020, de 3 de junio". Revista de Trabajo y Seguridad Social. CEF, núm. 449-450.

CANO GALÁN, Y., "Cambio jurisprudencial en relación con el reconocimiento de condiciones más beneficiosas en el ámbito de la Administración Pública”. Diario la Ley, no 9080, 2017.

GONZÁLEZ DEL REY RODRÍGUEZ, I., "La contratación de investigadores por universidades públicas en la Ley de la Ciencia de 2011". Revista de Trabajo y Seguridad Social. CEF, núm. 44, 2016.

GONZÁLEZ ORTEGA, S., "El régimen jurídico del personal del SUE y del SECTI a estudio: modalidades contractuales y categorías profesionales en el ámbito del SUE y del SECTI”, En AAVV., Disquisiciones jurídicas sobre el ámbito universitario. Cizur Menor (Navarra), Thomson-Reuters Aranzadi, 2016.

LÓPEZ INSÚA, B.M., "La precarización del personal investigador en formación de nuevo en el ojo del huracán: anomalía jurídica en la "codificación" de los contratos predoctorales". Derecho de las Relaciones Laborales, núm. 7, 2017.

LUJÁN ALCARAZ, J., "La contratación laboral del personal investigador ante la reforma laboral y la Ley de la Ciencia”, En HORGUÉ BAENA, C., BONACHERA LEDRO, M.I. y CARO MUNOZZ, A.I. (Coords.), Impacto de la nueva legislación en la educación superior y la investigación. Sevilla, Universidad de Sevilla, 2012.

MOLINA NAVARRETE, C., "Empleo público temporal y estabilidad obligacional: la indemnización por fin de contrato o de nombramiento", En CARO MUÑOZ, A.I (Dir.) y ROMERO BURILLO, A.M. y BELLO PAREDES, S. (Coords.), La articulación de la gestión universitaria a debate. Cizur Menor (Navarra), Thomson Reutres-Aranzadi, 2018.

MORENO GENÉ, J., "El tratamiento del "personal investigador contratado" en la negociación colectiva de las universidades". Aranzadi Social, núm. 9, 2007.

MORENO GENÉ, J., "La contratación laboral de los investigadores en la Ley de la Ciencia, la Tecnología y la Innovación: ¡el final del estado de excepción laboral en la ciencia?”. Revista de Trabajo y Seguridad Social. CEF, núm. 340, 2011.

MORENO GENÉ, J., "El contrato predoctoral: una modalidad específica de contrato formativo para los investigadores". Aranzadi Social, núm. 3, 2012.

MORENO GENÉ, J., "La aplicación de la doctrina "de Diego Porras" a investigadores y profesores universitarios: extinción de derechos o consolidación de carencias". Revista General del Derecho del Trabajo y de la Seguridad Social, núm. 48, 2018.

MORENO GENÉ, J., "Balance de diez años de negociación colectiva del PDI laboral en las Universidades Públicas”, En XI y XII Seminarios sobre aspectos jurídicos de la gestión universitaria. Thomson-Reuters Aranzadi, Cizur Menor (Navarra), 2018.

MORENO GENÉ, J., "La ambigua naturaleza jurídica del contrato predoctoral y su incidencia a efectos indemnizatorios”. Revista de Trabajo y Seguridad Social. CEF, núm. 431, 2019.

MORENO GENÉ, J., "La naturaleza jurídica y efectos indemnizatorios del contrato predoctoral: el debate continúa: Comentario a la Sentencia del Tribunal Superior de Justicia de Galicia de 11 de abril de 2019”. Revista de Trabajo y Seguridad Social. CEF, núm. 436, 2019. 
MORENO GENÉ, J., El estatuto del personal investigador predoctoral en formación: aspectos jurídicolaborales y de seguridad social. Barcelona, Atelier, 2020.

MORENO GENÉ, J., "La indemnización por finalización del contrato predoctoral. Fin del debate: Comentario a la Sentencia del Tribunal Supremo 903/2020, de 13 de octubre". Revista de Trabajo y Seguridad Social.CEF, núm. 454, 2021, págs. 154 a 163.

REQUENA MONTES, O., "Aproximación crítica al Estatuto del Personal Investigador Predoctoral en Formación". Revista General del Derecho del Trabajo y de la Seguridad Social, núm. 53, 2019.

SERRANO ARGÜELLO, M., "Modalidades específicas de contratación laboral del personal investigador. De la precarización al desideratum de su estabilidad en el empleo y consolidación profesional”. Revista General del Derecho del Trabajo y de la Seguridad Social, núm. 36, 2014.

SIRVENT HERNÁNDEZ, M., "Las modalidades de contratación laboral previstas en la LCTI específicamente para el personal investigador", En AAVV., El estatuto profesional del personal investigador contratado en régimen laboral. Madrid, Innap Investiga, 2016. 